\title{
Sustainability of the Pension System \\ in the Republic of Macedonia: \\ Challenges and Solutions
}

\author{
Hyrije Abazi-Alili
}

South East European University, Macedonia

h.abazi@seeu.edu.mk

Shpresa Alija

South East European University, Macedonia

s.alija@seeu.edu.mk

Abdylmenaf Bexheti

South East European University, Macedonia

a.bexheti@seeu.edu.mk

Irina B. Panovska

Lehigh University, USA

irp213@lehigh.edu

Remzije Rakipi

South East European University, Macedonia

r.rakipi@seeu.edu.mk

The aim of the study is to create a forecasting model that will foresee the trend of the situation of the Pension, Insurance and Disability Fund of the Republic of Macedonia. The methodology applied to evaluate the sustainability of pension system, and controlling the risk to pension funds, is forecast of all individual regressors through first order autoregressive model. This method will enable the assessment of the future uncertainty of the contributions and expenditures of pension insurance. The forecasted data show that in 2056, if no other reforms are undertaken, the increase in the percentage points of the number of employers is less than the increase in the number of pensioners for 3.9 percentage points. As per the natality and mortality, in the Republic of Macedonia natality will be only one third of its statistics in 2016, whereas mortality will double its value by 2056 .

Key Words: pension sustainability, postponed retirement, contributions and expenditures, financial and demographic forecasting, transition economy

JEL Classification: H55, J26, J11

https://doi.org/10.26493/1854-6935.16.173-187 


\section{Introduction}

The pension system represents a constant challenge both for lawmakers, regulators and pensioners. The main struggles of the pension and retirement policies are to provide adequate income in old age while at the same time guaranteeing financial sustainability and keep high level of employment. The key dilemma of many developed and transitional countries is precisely the direction of the development of the pension system, namely its structure and performance.

Since the founding of the pension system in the Republic of Macedonia, it has been operating on the basis of the principle of solidarity between generations and aims to create funds for pensioners and to maintain the almost equal level of living.

The pension system, according to Gora (2008) is a tool that divides the current GDP between the working generation and the pensioners. $\mathrm{He}$ also emphasizes that the higher share of GDP allocated to the inactive would enable the lower remuneration of production factors supplied by the active, which has consequences on economic growth, conditions in the labour market and the distribution of poverty. Furthermore, Blake (2006) claims that the distribution of the GDP between the working generation and the pensioners is elaborated in-depth by the overlapping generation model (OLG), as a very powerful tool to analyse pension systems.

The sustainable development of the pension system has a close relationship with social harmony as well as economic sustainable development (Dorfman et al. 2013). Therefore, keep long-term balance of contributions and expenditures of the pension system is crucial for accomplishing sustainable development of the system, meaning that financial sustainability should be maintained.

The protection of the elderly is one of the most important part of the pension system (Grech 2010). Taking into consideration the acceleration of the aging evolution of the population, the pension fund is confronted with many challenges to maintain financial stability.

The operation based on the principle of solidarity was initially considered successful and challenging during its implementation, as the average life expectancy was approximately 55 years and the employed ratio was 7 : 1 pensioner. However, later on, due to changes in the demographic structure, difficulties were encountered in implementing the principle of solidarity between generations, stemming from an increase in average human life expectancy and a reduction in the employed-retired ratio. 
Demographic structural changes that directly determine the movement of pension income caused worsening in pension systems, the creation of debts on pension funds, i.e. the pursuit of pension reforms worldwide. By 2007 around 170 countries adopted and approved some reforms in their pension systems aimed at realizing the rights of pension and disability insurance for all generations, short-term and long-term realization of solvency, not to override the reinforcement of public confidence and stimulating the development of capital markets, thus encouraging economic growth.

The following section provides some literature review on the issue of the methodology used to forecast the sustainability of the pension system, and some factors that influence the financial sustainability. Section 3 describes the data and presents the methodology used in the study. Section 4 provides the findings and discussion of the results. The concluding remarks are provided in section 5 .

\section{Literature Review}

The pension system, i.e. the sustainability of the pension system continues to remain part of the economic discourse. Population aging presents the main problem, which become even more difficult if it is accompanied by a PAYG scheme. It also known that in recent decades the financial sustainability of pension systems, in developed and developing countries is permanently threatened by the demographic factors (such as fertility, life expectancy, old-age, dependency ratio) and by the slowdown of growth rates economy.

Consequently, many countries have adopted radical reforms in their pension systems which are currently being implemented. The reforms in question had to do precisely with the transformation of pension systems from the nonfinancial model to the hybrid (financing and nonfinancing), or completely into the financial model. However, this transformation of pension systems has not yet been able to solve the problem of insolvency of pension system, because the demographic factors are not the only source of this lack of ability, which means that this insolvency includes a set of others factors such as labour market factors, national product, educational attainment, income adequacy of pensions, etc.

According to the International Monetary Fund Report (2012), 'Threats to financial stability from longevity risk derive from at least two major sources: one is the threats to fiscal sustainability as a result of large longevity exposures of governments (which, if realized, could push up 
debt-to-GDP ratios more than 50 percentage points in some countries) and the second factor is possible threats to the solvency of private financial and corporate institutions exposed to longevity risk. The latter, make us aware that longevity risk threatens to undermine fiscal sustainability of pension systems in the coming years and decades and complicating the longer-term consolidation efforts in response to the current fiscal difficulties. Therefore, reforms of the pension system model are intended to challenge these inappropriate demographic trends and are expected (the funded or at least partly funded) to prove resistant to negative demographic factor.'

Thus, relying on the Diamond-Samuelson olg model, when labour supply and retirement are exogenous and when a state pension system that is fully funded is introduced, there will be no change to the dynamic path of the economy, which means that it is impossible to move from an unfunded to a funded pension scheme without making the transition generation worse off. Instead, when labour supply and retirement are endogenous, and respond to the taxes, as is possible to move gradually from an unfunded to a funded scheme.

So, what happens during the transition from PAYG schemes into fully funded pension schemes? The latter, is well argued by Feldstein and Liebman (2001) in a paper where they asses the theoretical and empirical implications of the transition from the PAYG schemes into fully funded pension schemes with investment-based individual savings accounts, where they highlighted the fact that even though the introduction of the PAYG schemes (which benefitted older age cohorts), a considerable strain is imposed on the younger generations facing a small internal rate of return on mandatory contributions into PAYG public schemes.

However, in both, the unfunded and funded pension system there is no other way of pension funding than through GDP distribution, even if the distribution differs from these systems. Thus, in the unfunded system, the distribution occurs without the involvement of the financial market - based on the promises that in return for the submitted contributions, a pension benefit will be paid out in the future). While in the funded model the distribution is made with the participation of the financial market, and the amount of the future pension benefit received in return for the contributions, depends on the rate of return on this market. Barr and Diamond (2006), emphasize the way of how the distribution is conducted between the working generation and the pensioners, i.e. the mentioned promise of sharing part of the future GDP with the generation of pen- 
sioners that may be given by children to their parents, by businesses to their employees, and by the government to citizens - depending on the type of pension security.

In general, the theoretical aspect of the pension systems (including the factors that affect it), help us recognize another important factor for the solvency of pension systems, which are the pension expenditures as a result from the distribution of the current GDP between the pensioners and the working generation (by not excluding the other factors which have a crucial impact in increasing or decreasing the participation of pension expenditures in GDP, such as labour market, the level of GDP growth, income adequacy of the pension system, education of people, etc.). Education, as another factor that affects the pension expenditures relates to the equality and rationality of pension decisions that may affect the distribution of current GDP, i.e. the pensioners' participation in funds. According to Blake (2006), better education is one of the factors extending life expectancy. The latter, let us know that in countries with a higher percentage of educated people, the pension expenditures are expected to be higher, which may be attributed to the fact that educated people, live longer. However, the best way of analysing the pension expenditures is through measurement. There are various ways to assess the financial sustainability of pension systems. The other way of measurement of pension expenditures is by comparing the results from equations of pension system incomes from contributions and expenses for pension benefits, which was used by e.g. De la Fuente (2011). Further, measuring the pension expenditures in absolute values or in relation to GDP, is definitely more legitimate because enables comparing these expenses throughout many countries with various GDP's.

Taking in consideration the findings of the authors related to the oldage pension expenditure as well as based on the pension economy theory, we may list some of the important groups of factors determining pension expenditure, such as demographics, the labour market, GDP and its growth, income adequacy of pensions and education. Although, the concerned factors do not exhaust the issue of pension system solvency determinants, nevertheless they seem to be of highest significance in the context of pension reforms.

Therefore, to evaluate the sustainability of pension systems, different models and perspectives are now being used, reflecting different results (Long and Pfau 2008). For example, Lee and Tuljapurkar (1994) in their successive studies, to see the impact of demographic change on the finan- 
cial sustainability of the Us pension system, by creating stochastic forecasts for mortality and using a deterministic forecast for net immigration, made a prediction of the Us population, for the period 1994-2070.

Furthermore, Fehr and Habermann (2004), using the combination of demographic and economic factors, dealt with the sustainability of the German pension system under the influence of the uncertainty of demographic factors for the period 2001-2050. So, the authors use stochastic forecasts for fertility and mortality, while an overlapping generation model (including 3 sectors: household, production, and government) is used for economic variables. The results found that demographic changes play an important role in the level of benefits for the long term, suggesting concentration in contribution rates and replacement rates.

The Asset-Liability Model (ALM) with stochastic simulation is used for analysing the Japanese pension scheme by Chia, Kitamura, and Tsui (2004). The authors take in consideration different variables (growth rate of wages, investment return, etc.), to determine an appropriate index of pensions, which at the same time will affect the level of future benefits and the financial sustainability of the scheme. Also, Børlum (2004), following the previous author's methodology, in his study of the Danish pension system, came to the conclusion that the insecurity of demographic factors has a significant impact on long-term profit levels.

However, Moscarola (2009) in assessing the sustainability of the Italian pension system, use Microsimulation Model, which came to conclusion that cohorts that fall completely under the new system accrue present value ratios calculated at the $1.5 \%$ real interest rate of around 1 on average. Also, Fernandez-Diaz, Patxot, and Souto (2013) by using the previous model (DyPeS, the first dynamic microsimulation), in assessing the sustainability of the Spanish pension system came to the conclusion that in the simulations adopted in 2011 only the increase of retirement age (from 65-67) will have an important effect on pension expenditures, while the other measures applied in calculating the initial pension for new retirees have a limited impact.

A microsimulation model is used by Hanappi, Müllbacher, and WinterEbmer (2012), for assessing Austria's pension system. The data was collected by the Austrian social security database (ASSD). The implementation of this model enables the calculation of the pension benefits rights for each individual. During the simulation of some pension reform scenarios, they noted that a stronger emphasis on the financial incentives of the pension system (bonuses or additional deductions) reduces the out- 
of-labour-force ratio of individuals aged $55-65$ by $16.3 \%$ for females and $13.4 \%$ for males. So, for measuring the financial sustainability of pension systems, different authors employ different models (Overlapping Generation Model, Life cycle model, Microsimulation model, Stochastic forecasting model etc.), which also come with different findings, depending on the problem's point of view. In our study, we apply individual forecast of all individual regressors, to evaluate the trends of the pension system of Republic of Macedonia.

The variables employed are: number of pensioners, number of employers, budget income, income from pension contributions, expenditure for pensions, pension age factor, etc. Hence, the generated results will serve as recommendation for the Republic of Macedonia, i.e. in order to achieve financial consolidation of the pension system RM will need to either: (i) raise the contribution rate, actually return to the previous rate of $21.2 \%$; increasing the age retirement, or in parallel, increasing the contribution rate and increasing the retirement age.

\section{Data Analysis and Methodology}

The aim of this study is to provide forecast of all individual regressors using basic arima models, to evaluate the trends of different variables related to the pension system of the Republic of Macedonia. A time series is a sequence of measurements of the same variables made over time. The measurements of the data employed in this paper are yearly. Generally, an autoregressive model is when a value from a time series is regressed on previous values from that same time series.

$$
y_{t}=\beta_{\mathrm{o}}+\beta_{1} y_{t-1}+\varepsilon_{t} .
$$

In this regression model, the response variable in the previous time period has become the predictor and the errors have the usual assumptions about errors in a simple linear regression model. The order of an autoregression is the number of immediately preceding values in the series that are used to predict the value at the present time. So, the preceding model is a first-order autoregression, written as $\mathrm{AR}(1)$.

The data employed for the estimation of AR(1) are historical timeseries annual data for financial and demographical characteristics of the Macedonian population for the period 1994 until 2016. The data are available from official sources such as the Pension and Disability Insurance Fund, State Statistical Office and Ministry of Finance of the Republic of Macedonia. 
Number of Pensioners Data. This paper takes the number of pensioners data from 1994 until 2016. According to the data the number of pensioners has increased from 216.83 thousand in 1994 to 305.77 thousands of pensioners in 2016, indicating that there is an increase of approximately $41.2 \%$.

Number of Employers Data. In order to have a comparative indication of employer-to-pensioner ratio, statistics on the number of employed persons are provided. In the Republic of Macedonia, there is an increase on the number of employers from 468 thousand in 1994 to 570 thousands of employers in 2016, indicating that there is an increase of approximately $21.8 \%$.

Number of Employers per Pensioners Data. As it can be seen from the above mentioned variables, because of the higher increase in the trend of the number of pensioners than the numbers it is expected that this ratio will decrease. That is, a decrease from 2.2 in 1994 to 1.9 in 2016. This is the most concerning ratio between the number of employers and number of pensioners from the beginning of transition when it was 3:1 until 1.9:1 (1.9 of the employers pay contribution for every pensioner in the Republic of Macedonia). This ratio is even worse in 2002 being 1.3:1 (the years after the conflict in the country). However, due to the Ohrid Framework and increase in the employment in the public sector there is a slight improvement in this ratio (Centre for Regional Policy Research and Cooperation 'Studiorum' 2011).

Natality Data. There is a decreasing trend of Natality in the Republic of Macedonia. Specifically the natality has fallen from 31 thousand in 1994 to 23 thousands of inhabitants in 2016 , i.e. decreasing rate of $25.8 \%$ for the years under analysis.

Mortality Data. On the other hand, there is an increasing rate of mortality from 15.6 in 1994 to 20.4 thousand in 2016, indicating that there is an increase of approximately $30.7 \%$.

Budget Income Data. The data consists of four financial variables. One of them is budget income. The trend is positive, i.e. there is a considerable increase from 2,944.6 in 1994 to 26,599.5 (in thousands of denars, 100 denar $=1.62$ euro) in 2016 .

Income From Pension Contributions. The other financial variable is income from pension contributions. Again, the trend is positive, i.e. there is an increase from $13,634.7$ in 1994 to $32,488.8$ (in thousands of denars) in 2016.

Total Budget Expenditure. The data on total budget expenditure show 

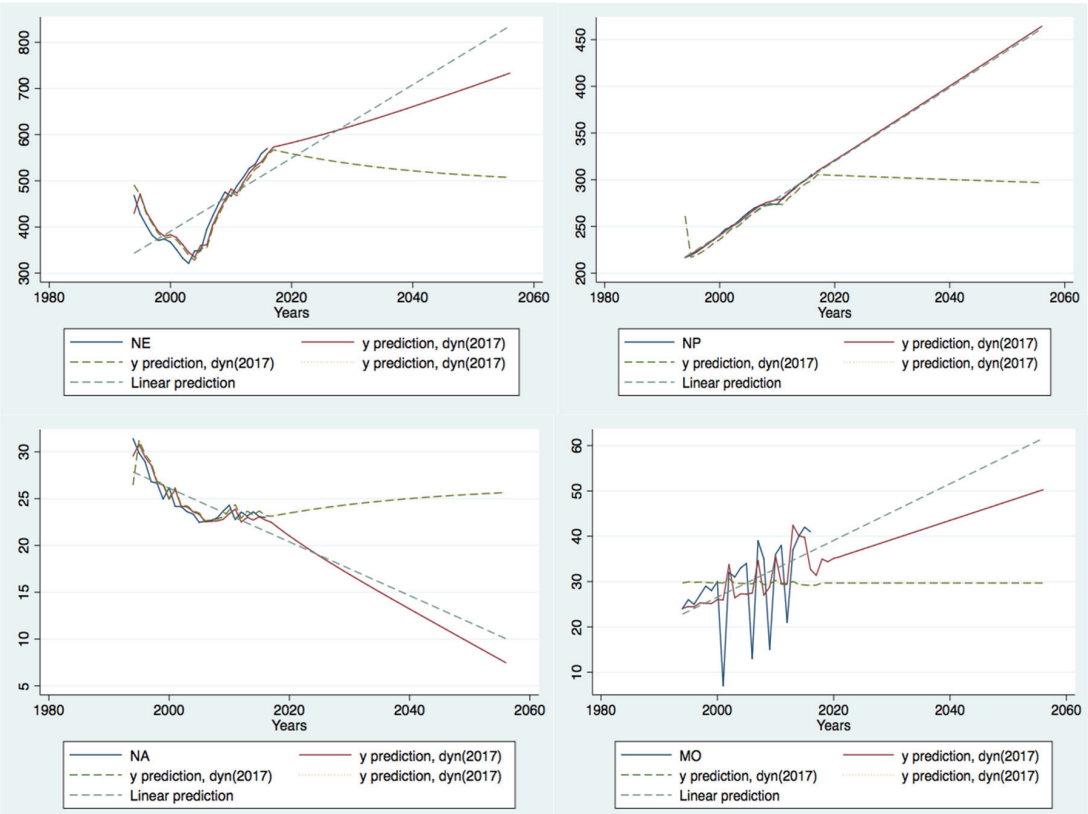

FIGURE 1 Forecasts of the Demographic Characteristics of the Population in the Republic of Macedonia (solid blue lines ending in 2016 actual values, solid red line and dashed lines - forecast values)

an increase from 18,444.5 in 1994 to 61,488.4 thousands of denars in 2016.

Expenditure for Pensions. Expenditures for pensions have increased since 1994, from 15,404.4 to 48,248.2 in thousands of denars in 2016. However, if considering the participation of the expenditures for pensions on total budget expenditure, it has decreased from $83.5 \%$ to $78.5 \%$, i.e. for five percentage points.

\section{Findings and Discussion}

Using the statistical software STATA the authors provide forecast for the individual regressors. Using arima and regression model allowed us to generate a forecast for all the variables described in the methodology.

The graphs in figure 1 present the results of the actual values and also denote the forecasted values. The graphs are grouped in financial variables and demographics. Specifically, figure 1 demonstrates the predictions of the demographic characteristics of the population in the Republic of Macedonia.

The autoregressive term has a $p$-value that is less than the significance level of 0.05. One can conclude that the coefficients for the autoregressive 
term are statistically significant, and the terms are kept in the model. The approach used is $\mathrm{AR}(1)$ model adopted to estimate the forecast of all individual regressors, starting from demographic characteristics. The employers per pensioners' data variable have the Wald chi-square 97.85 .

By using historical data for the period of 1994 until 2016 the arima $L 1$, coefficient shows significant statistical estimates at $1 \%$ level of significance for the variable employers per pensioners' data. The expected decrease in this ratio being 1.9 in $\mathbf{2 0 1 6}$ has resulted in further decrease of the forecasted values. Thus the forecasts of the employers per pensioners' data in 2056 is predicted to be 1.27 . It means that 1.27 of the employers will pay contribution for every pensioner in the Republic of Macedonia (almost 1:1) by 2056 in no reforms are undertaken on the system itself.

The same calculations are provided for the number of pensioners. For the period of 1994 until 2016 the arima L1, coefficient shows significant statistical estimates at $1 \%$ level of significance for the number pensioners data. The increase of approximately $41.2 \%$ to 305.77 thousands of pensioners in 2016, gives an expectation of further increase of the forecasted data. Accordingly, the forecasts of the number of pensioners data in 2056 is predicted to become 464.28 thousands of pensioners, indicating that there will be an increase of approximately $51.8 \%$ on the number of pensioners for the forty years of forecast in the Republic of Macedonia.

On the other hand, there was an increase on the number of employers to 570 thousands of employers in 2016. This variable has also statistical significant evidence at $1 \%$ level of significance at the lagged variable using arima. The forecasted value show evidence that in 2056 the number of employers is going to be 733 thousand, indicating that there will be an increase of approximately $28.5 \%$. The increase in the percentage points of the number of employers is less than the increase in the number of pensioners for 3.9 percentage points.

As per the natality and mortality, the forecasts based on the historical data provide sufficient statistical evidence to foresee that in the Republic of Macedonia natality will be only one third of its statistics in 2016, whereas mortality will double its value.

Figure 2 presents the financial parameters of the pension system in the Republic of Macedonia. Thus showing the following: total income, budget income, income from pension contributions and expenditures for pensions. There is a slight disparity in these indicators.

The historical data of the variable budget income showed inconsistency 

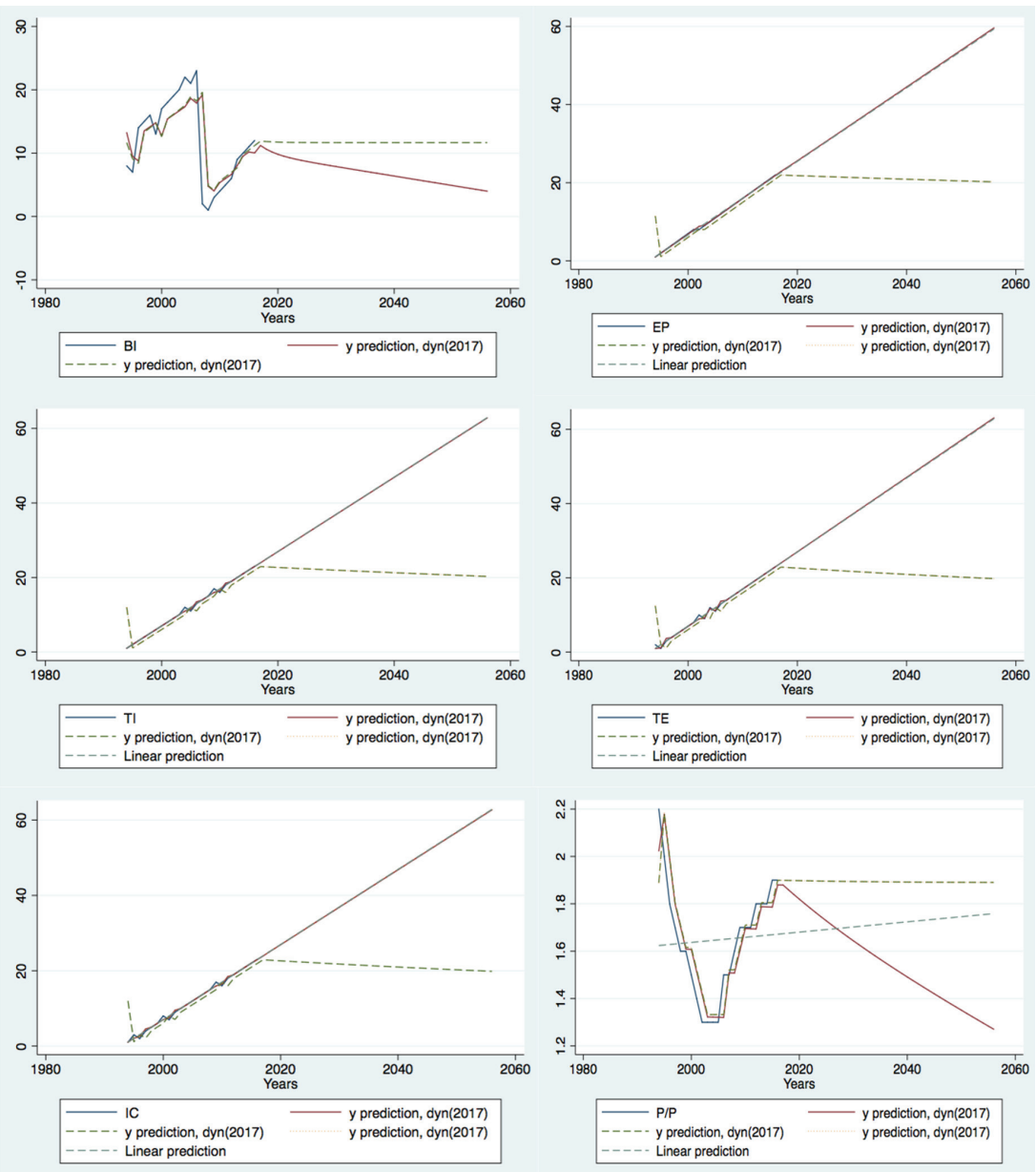

FIgURE 2 Forecasts of the Financial Parameters of the Pension System in the Republic of Macedonia (solid blue lines ending in 2016 - actual values, solid red line and dashed lines - forecast values)

by 2016. The arima $L 1$ coefficient shows significant statistical estimates at $1 \%$ level of significance for the variable employers per pensioners' data. The final result in 2056 is a decrease to one third of its value in 2016 .

Contrary to this, the total income historical data indicated an increase by 2016 . The arima $L 1$ coefficient shows significant statistical estimates at $1 \%$ level of significance for the total income variable. The forecasts of the total income in 2056 indicate that there will be an increase of approximately three times more for the forty years of forecast in the Republic of Macedonia. 
Income from pension contributions. This variable has also statistical significant evidence at $1 \%$ level of significance at the lagged variable using arima. The forecasted value show evidence that in 2056 the number of employers is going to be 733 thousand, indicating that there will be an increase of approximately $28.5 \%$. The increase in the percentage points of the number of employers is less than the increase in the number of pensioners for 3.9 percentage points.

The forecasts of expenditure for pensions, based on the historical data provide sufficient statistical evidence to foresee that in the Republic of Macedonia the expenditure for pension are increasing and thus will double its value by 2056 .

\section{Conclusion}

Taking into consideration the challenges that the pension system is facing, the key dilemma of many developed and transition countries remains precisely the direction of the development of the pension system, structure and performance. Pension reforms represent a dynamic and persistent category, which is encountered in developed, developing and transition countries. Even over the last decade, they are even more intensive, especially in terms of structure review, mobilization of resources to overcome demographic and financial difficulties, and preparation of a system that will provide a solution to the problems in the medium to long term.

Thus, pension reforms aim at realizing the rights to pension and disability insurance for all generations, short-term and long-term solvency performance, enhancing public confidence and stimulating the development of capital markets, and thus encouraging economic growth.

The reasons that led to the need for a contribution scheme could be channelled from a traditional, modern and corporate viewpoint. In traditional societies, families or communities took care of individuals who reached old age, but with its modernization people moved around communities leaving the elderly without an adequate security net. Consequently, the government underwent the provision of a type of pension system by directly supporting pensions or mandating their participation in pension plans provided by employers or private pension providers resulting from the 'myopia' and 'moral hazard' phenomenon. Whereas, according to corporate outlook, pension schemes were created as a preventive measure by the insecurity of retirement income, labour force, and the need to create an efficient saving system. 
The objectives of the pension system are often frustrated with social protection, which also addresses the challenges of poverty, vulnerability and social exclusion. However, there are substantial differences between pension and social protection in terms of administration and funding. In terms of administration, although some social protection programs may resemble pensions, yet they are not administered as a pension scheme. Social protection offers a wide range of benefits, one of which is benefit for the elderly, while pensions represent benefits that are provided by the individual by paying in a pension scheme or paid by the employer.

As far as administration is concerned, the main responsibility lies with the Ministry of Labour and Social Policy, while social security rights and services are provided through the Pension and Invalidity Insurance Fund, the Health Insurance Fund and the Employment Agency in the Republic of Macedonia.

In terms of funding, pensions are funded in various ways by contributing to a pension scheme or opening a bank account as a saving form that will play the role of retirement age, while social protection is a government program, and consequently, a special budget line is allocated for financing the programs provided by the Ministry of Labour and Social Policy. Thus, pensions are funded by the employer or by the government depending on the agreement on the use of funds, while the social protection programs are funded from the budget in the republic of Macedonia.

The need to transform the PAYG system into a fully funded pension scheme, namely the savings-investment link, resulted in the creation of a classic, neoclassical and alternative model.

Republic of Macedonia is considered to be one of the countries with the lowest contribution rate, so to achieve financial consolidation one of the recommendations would be precisely to return to the previous contribution rate of $21.2 \%$ (which is $18 \%$ currently) and increase the retirement age. This recommendation, on the one hand, would affect the growth of the number of employees, above all of the old generation, while on the other hand, will cause reduction on the number of pensioners, consequently reducing the costs.

\section{References}

Barr, N., and P. Diamond. 2006. 'The Economics of Pensions.' Oxford Review of Economics Policy 22 (1), 15-39.

Blake, D. 2006. Pension Economics. Chichester: Wiley.

Børlum, M. (2004). 'Demographic Uncertainty and the Sustainability of 
the Danish Pension System: A Stochastic Approach.' Centre for Economic and Business Research Working Paper, Copenhagen Business School, Frederiksberg.

Centre for Regional Policy Research and Cooperation 'Studiorum.' 2011. 'Effective Political Participation of the Small(er) Ethnic Communities in Local Self-Government in the Republic of Macedonia: The Impact of the Ohrid Framework Agreement.' Centre for Regional Policy Research and Cooperation 'Studiorum,' Skopje.

Chia, N., Y. Kitamura, and A. K. C. Tsui. 2004. 'The Pension System in Japan and Retirement Needs of the Japanese Elderly.' Paper presented at the Workshop on Ageing and the Status of the Older Population in Southeast Asia, Singapore, 22-23 November.

De la Fuente, A. 2011. 'A Simple Model of Aggregate Pension Expenditure.' GSE Working Paper 553, Barcelona Graduate School of Economics, Barcelona.

Dorfman, M., R. Holzmann, P. O’Keefe, D. W. Wang, Y. Sin, and R. Hinz. 2013. China's Pension System: A Vision. Washington, DC: World Bank.

Fehr, H., and C. Habermann. 2004. 'Pension Reform and Demographic Uncertainty: The Case of Germany.' Journal Pension Economic Finance 5 (1): 69-90.

Feldstein, M. S., and J. Liebman. 2001. 'Social Security.' NB E R Working Paper 8451, National Bureau of Economic Research, Cambridge, MA.

Fernandez-Diaz, F. J., C. Patxot, and G. Souto. 2013. 'Dy PEs: A Microsimulation Model for the Spanish Retirement Pension System.' Working paper 2013-06, FEDEA, Madrid.

Gora, M. 2008. 'Retirement Decisions, Benefits and the Neutrality of Pension Systems.' E NE PR I Research Report 51, Centre for European Policy Studies, Brussels.

Grech, A. G. 2010. 'Assessing the Sustainability of Pension Reforms in Europe.' PhD thesis, The London School of Economics and Political Science, London.

Hanappi, H. T., H. S. Müllbacher, and R. Winter-Ebmer. 2012. 'I H S Microsimulation Model for Retirement Behaviour in Austria.' Final report, Institute for Advanced Studies, Viena.

International Monetary Fund. 2012. Global Financial Stability Report: The Quest for Lasting Stability. Washington, DC: International Monetary Fund.

Lee, R. D., and S. Tuljapurkar. 1994. 'Stochastic Population Forecasts for the United States: Beyond High, Medium, and Low. Journal of the American Statistical Association 89 (428): 175-89.

Long, G. T., and W. D. Pfau. 2008. 'Demographic Changes and the LongTerm Pension Finances in Vietnam: A Stochastic Actuarial Assess- 
ment.' Discussion paper 08-05, GRIPS Policy Information Center, Tokyo.

Moscarola, F. C. 2009. 'Measuring the Sustainability of Pension Systems through a Microsimulation Model: The Case of Italy'. ENEPRI Research Report 66, The European Network of Economic Policy Research Institutes, n. p.

This paper is published under the terms of the Attribution-

NonCommercial-NoDerivatives 4.o International (CC B Y-NC-ND 4.0)

License (http://creativecommons.org/licenses/by-nc-nd/4.o/). 